\title{
Genotype by trait biplot analysis to study associations and profiles of Ethiopian white lupin (Lupinus albus L.) landraces
}

\author{
Mulugeta Atnaf*1,2, Kassahun Tesfaye ${ }^{2}$, Kifle Dagne ${ }^{2}$, Dagne Wegary ${ }^{3}$ \\ ${ }^{1}$ Ethiopian Institute of Agricultural Research, Pawe Research Center, P. O. Box 25, Pawe, Ethiopia \\ ${ }^{2}$ Addis Ababa University, College of Natural Sciences, Department of Microbial, Cellular and Molecular Biology, \\ P.O. Box 1176, Addis Ababa, Ethiopia \\ ${ }^{3}$ CIMMYT-Ethiopia, ILRI Campus, CMC Road, P.O. Box 5689, Addis Ababa, Ethiopia
}

\author{
*Corresponding author: atnafmulugeta@gmail.com
}

\begin{abstract}
Limited information is available on trait relations and profiles of white lupin landraces in tropical growing conditions including Ethiopia. The objectives of this study were to understand the relationships among traits, and to document trait profile of Ethiopian white lupin landraces. As a component of this study, two sets of experiments were conducted. The first comprehensive experiment that consisted of 143 accessions collected from major lupin growing areas of Ethiopia was evaluated at Merawi and the second experiment that consisted of 12 selected accessions was evaluated across six locations. In both experiments, significant variations were observed among the accessions for most studied traits. Higher heritability and genetic advance as percent of mean was observed for grain yield, indicating the possibility of improving this trait through selection. Genotype by trait biplots captured 55\% - 66\% of the variations due to genotype by trait interactions. Trait association and trait profile biplots were constructed for highland, mid altitude and low land environments, and across all locations. Different patterns of associations and genotype (accession) by trait interactions were observed in different environments. However, genotype by trait biplots consistently indicated that grain yield had positive associations with most of the traits; especially, with number of pods per plant, plant height and seeds per pod. The study identified some accession with desirable performances as good for specific trait and/or trait groups that could be considered as sources of genes for the traits they have best performed. G8 consistently showed higher grain yield, G2 had higher number of branches and higher number of seeds per plant, G7 had more number of pods per plant and larger seed size and G4 produced longer pods. The accessions used in this study were found to be useful sources for genetic variability for future breeding that targets to improve grain yield and other agronomic traits of white lupin in Ethiopia.
\end{abstract}

Keywords: Ethiopia; Genotype by location interaction; Mega-environment; Selection; Trait inheritance.

Abbreviation: EBI_Ethiopian Biodiversity Institute; GCV_Genotypic coefficient of variation; GGE_Genotype plus Genotype by Environment interaction; GT_Genotype by Trait; PCV_Phenotypic coefficient of variation; PC_Principal component.

\section{Introduction}

Most challenges in plant breeding can be summarized into two main categories. One is genotype-by-environment interaction on key traits, and the other is undesirable associations among desired traits (Yan, 2014). Genotype evaluations on the basis of multi-environment trials and multiple traits are important components in plant breeding (Yan et al., 2000; Yan and Rajcan, 2002). Effective interpretation and utilization of the multi-environment trial data based on multi-variate considerations are very crucial at all stages of plant breeding. Yet, accurate estimation, interpretation, and decision making of such data remain a major challenge to breeders (Yan and Rajcan, 2002). Interrelationships among specific breeding objectives mostly impact choice of selection and breeding methods. If all breeding target traits were either positively correlated, or independently inherited, selection would not be much more difficult than selecting for a single trait. However, strong negative correlations between key traits often exist, which make breeding and selection very challenging (Lewis, 2006). Understanding of the genetic variations between and within populations is key for any breeding strategy (Xiao et al.,
2008), and it is important to ascertain the variations available in terms of agronomic and plant structure traits (Rubio et al., 2004). Heritability of a trait is important in estimating its response to selection, and genetic improvement of quantitative traits requires reliable estimates of heritability. It estimates the relative magnitude of genotypic and phenotypic variance for the trait and gives an idea of the total variation accounted to genotypic effects (Allard, 1960).

Numerous methods have been used to understand trait relations and overall genotype profile of different crops. Recently, a genotype by trait (GT) biplot, which is an application of the GGE biplot technique, is becoming an effective tool for exploring multi-trait data (Yan and Kang, 2003). It graphically displays the genotype by trait table as a biplot, and allows the visualization of the associations among traits across the genotypes (Yan and Rajcan, 2002), and trait profile of the genotypes (Ma et al., 2004; Rubio et al., 2004; Yan and Frégeau-Reid, 2008; Yan and Kang, 2003). It also provides information on the usefulness of cultivars for production as well as generates information that helps to detect less important (redundant) traits, and identify those 
that are appropriate for indirect selection for a target trait. The GT biplot has been utilized to study trait relations and genotype evaluation in several crop species including soybean (Yan and Rajcan, 2002), white lupin (Rubio et al., 2004), common bean (Hirpa et al., 2013; Gonzalez et al., 2006), cowpea (Oladejo et al., 2011), durum and bread wheat (Akcura, 2011; Reza et al., 2011), and aromatic peppers (Abu et al., 2011).

White lupin is a promising leguminous crop for human consumption, green manuring, forage and has substantial importance in human nutrition and health (Hall, 2005; Lqari et al., 2005; Johnson et al., 2006). It has been traditionally cultivated for several thousands of years in the Mediterranean region, and along the Nile valley where it has been originated (Kurlovich, 2002; Wolko et al., 2011). It is produced in Ethiopia exclusively by smallholder subsistence farmers, mainly for its food grain and soil fertility maintenance values (Atnaf et al., 2015a; Yeheyis et al., 2010). The local varieties being used by farmers have several undesirable characteristics, such as low yield potential, susceptibility to major diseases (Atnaf et al., 2015b) and high contents of alkaloids (Yeheyis et al., 2012). Therefore, there is a need to develop well adapted white lupin varieties with farmers' preferred traits including high grain yield, low alkaloids level and resistant to major lupin diseases.

Significant intra-specific variations were reported among Ethiopian white lupin landrace accessions (Atnaf et al., $2015 \mathrm{~b}$ ) and also among accessions from other parts of the world (Raman et al., 2014; Rubio et al., 2004) for grain yield, disease resistance and other important agronomic traits. Several researchers studied the relationships among agronomic traits in white lupin (Annicchiarico et al., 2010; Gonzalez-Andres et al., 2007; Rubio et al., 2004). The results of these studies indicated that the relationships among white lupin traits are consistently influenced by the unpredictable conditions of the growing environments. Thus, genotype selection should be based on multiple trait data in variable environments within the target regions. However, little is known about trait relations and trait profiles of white lupin genotypes in tropical growing conditions including in Ethiopia. The objectives of this study were two folds:1) to understand the relationships among traits in Ethiopian white lupin landraces, and (2) to assess trait profile of Ethiopian white lupin landraces. The information generated would be used to design improvement strategies of white lupin in Ethiopia that focus on grain yield and other important agronomic traits.

\section{Results and Discussion}

Significance differences were observed among the Ethiopian white lupin landraces for the 10 agronomic and phenological traits studied except for pod diameter in the first experiment. Details of analysis of variance and mean performances of these landraces were previously reported by Atnaf et al. (2015b). Hence, this paper mainly focuses on the study of trait relationships, and trait profiles, inheritance and gain from selection among Ethiopian white lupin landraces evaluated under two sets of experiments.

\section{Estimates of variance components, heritability and genetic advance}

Phenotypic coefficients of variations (PCV) were higher than genotypic coefficient of variation (GCV) for all traits studied in both experiments (Table $1 \mathrm{a} \& \mathrm{~b}$ ). The differences between PCV and GCV were accounted to the environmental conditions under which the genotypes were grown. The extents of the difference between PCV and GCV indicate degree of environmental influences on the traits. The difference ranged from 0.61 in days to maturity to 8.42 in number of pods per plant which indicate significant environmental influence on the expression of number of pods per plant; whereas it was negligible for days to maturity. Very similar results were observed in the focused experiment executed across six different locations in Ethiopia (Table 1b). For the comprehensive experiment, phenotypic variability ranged from 3.87 for days to maturity to 17.66 for grain yield while it ranged from 0.86 to 34.61 in the focused experiment for the same traits. Genotypic variability ranged from zero for pod diameter to 13.05 for grain yield in the comprehensive experiment and from 0.68 for physiological maturity to 20.6 for grain yield in the focused experiment.

Estimates of broad sense heritability ranged from near zero for pod diameter to $85 \%$ for days to flowering for the comprehensive experiment (Table 1a). For the focused experiment, it ranged from $35 \%$ for pod diameter to $77 \%$ for days to flowering (Table 1b). Of the studied traits, days to flowering and maturity, and grain yield consistently exhibited high heritability in both experiments. Annicchiarico et al. (2010) reported high heritability for flowering time. High heritability indicates high proportion of genetic variance that could be inherited, and would be exploited by breeders to select superior genotypes based on phenotypic performance (Peter et al., 2008; Tazeen et al., 2009). Plant height showed moderate to high heritability for both experiments. Number of branches on the main axis, hundred seed weight, number of seeds per pod and pods per plant, and pod length showed moderate heritability, which depicts considerable influence of environment on the expressions of these traits. Contrary to the current findings, Annicchiarico et al. (2010) reported high broad sense heritability for seed weight in European white lupin genotypes. Heritability of pod diameter was zero for the comprehensive experiment, and low for the focused experiment, indicating the predominance of environmental effects more than that of genetic effects for the trait.

Estimates of genetic advance as percent of mean were high only for grain yield in both experiments; moderate to high for pods per plant (Table 1 a \& b). Days to flowering, plant height, hundred seed weight and number of branches on the main axis had moderate $(>10 \%)$ genetic advance for the comprehensive experiment, but low for the focused experiment; whereas all the other traits had low level of genetic advance in both experiments. Since high heritability does not always guarantee high genetic gain from selection, heritability should be considered combined with genetic advance in predicting selection for superior genotypes (Ali et al., 2002; Singh, 2000). In the present study, high estimate of GCV, heritability and genetic advance as percent of mean were observed only for grain yield while moderate heritability and genetic advance as percent of mean were observed for hundred seed weight, plant height and pods per plant. High heritability but low genetic advance as percent of mean were observed for days to flowering and physiological maturity; whereas moderate heritability and low genetic advance were realized for number of seeds per plant, pod length and number of branches on the main axis.

Panse (1957) stated that high heritability coupled with high genetic advance indicates the additive gene effects while high heritability coupled with low genetic advance indicates the non-additive gene effects for the control of a particular character. Accordingly, the presence of high estimates of $\mathrm{GCV}$, heritability and genetic advance as percent of mean for grain yield in this study indicate the preponderance of additive 
Table 1. Estimates of parameters of variability for different traits in Ethiopian white lupin landraces.

(a). Variability parameters in 143 white lupin landrace accessions at Merawi.

\begin{tabular}{|c|c|c|c|c|c|c|c|}
\hline \multirow[b]{2}{*}{ Traits } & \multirow[b]{2}{*}{ Minimum } & \multirow[b]{2}{*}{ Mean } & \multirow[b]{2}{*}{ Maximum } & \multicolumn{2}{|c|}{ Variability } & \multirow[b]{2}{*}{ Heritability (\%) } & \multirow[b]{2}{*}{ GAM } \\
\hline & & & & PCV & GCV & & \\
\hline$\overline{\mathrm{DF}}$ & 65.74 & 81.20 & 92.05 & 5.97 & 5.14 & 84.92 & 10.45 \\
\hline $\mathrm{DM}$ & 140.77 & 178.86 & 190.78 & 3.87 & 3.26 & 81.12 & 6.47 \\
\hline BR & 7.27 & 8.20 & 10.05 & 12.83 & 8.08 & 55.70 & 14.72 \\
\hline $\mathrm{PH}$ & 75.99 & 131.29 & 142.64 & 8.39 & 6.05 & 66.08 & 11.43 \\
\hline PD & 6.53 & 6.53 & 6.53 & 8.69 & 0.00 & 0.00 & 0 \\
\hline PL & 71.22 & 87.06 & 89.97 & 6.21 & 3.36 & 43.20 & 5.52 \\
\hline PP & 66.60 & 84.75 & 92.19 & 15.19 & 6.77 & 31.67 & 9.91 \\
\hline SP & 4.99 & 5.35 & 5.54 & 5.65 & 2.55 & 33.98 & 3.95 \\
\hline SW & 24.28 & 31.52 & 35.09 & 9.47 & 5.84 & 53.58 & 10.45 \\
\hline GY & 2.05 & 4.48 & 5.38 & 17.66 & 13.05 & 69.31 & 25.21 \\
\hline
\end{tabular}

(b). Variability parameters in 12 white lupin accessions evaluated across six locations in Ethiopia.

\begin{tabular}{|c|c|c|c|c|c|c|c|}
\hline \multirow[b]{2}{*}{ Traits } & \multirow[b]{2}{*}{ Minimum } & \multirow[b]{2}{*}{ Mean } & \multirow[b]{2}{*}{ Maximum } & \multicolumn{2}{|c|}{ Variability } & \multirow[b]{2}{*}{ Heritability } & \multirow[b]{2}{*}{ GAM } \\
\hline & & & & $\mathrm{PCV}$ & GCV & & \\
\hline $\mathrm{DF}$ & 57.50 & 60.32 & 64.25 & 2.93 & 2.29 & 77.12 & 4.65 \\
\hline DM & 164.25 & 167.10 & 169.25 & 0.86 & 0.68 & 72.60 & 1.29 \\
\hline BR & 3.71 & 4.87 & 5.86 & 9.85 & 4.99 & 39.40 & 7.99 \\
\hline PH & 105.85 & 128.00 & 146.90 & 7.30 & 4.05 & 48.17 & 7.25 \\
\hline PD & 6.05 & 7.31 & 8.47 & 7.11 & 4.33 & 35.49 & 5.20 \\
\hline PL & 66.85 & 75.20 & 83.10 & 4.72 & 2.63 & 62.87 & 6.12 \\
\hline PP & 31.45 & 64.26 & 93.55 & 21.29 & 13.31 & 60.70 & 26.62 \\
\hline SP & 3.58 & 4.91 & 5.74 & 9.37 & 5.31 & 45.34 & 8.76 \\
\hline SW & 17.25 & 22.81 & 27.90 & 10.65 & 6.89 & 44.35 & 9.73 \\
\hline GY & 1.25 & 2.63 & 4.39 & 34.61 & 20.60 & 75.50 & 53.83 \\
\hline
\end{tabular}
millimeter; $\mathrm{PL}=$ Pod length in millimeter; $\mathrm{PP}=$ Pods per plant; $\mathrm{SP}=$ Seeds per pod; $\mathrm{SW}=100$ seed weight in gram; $\mathrm{GY}=\mathrm{Grain}$ yield in ton per hectare; $\mathrm{PCV}=\mathrm{Phenotypic}$ coefficient of variation; $\mathrm{GCV}=$ Genotypic coefficient of variation; GAM= Genetic advance as percent of mean.
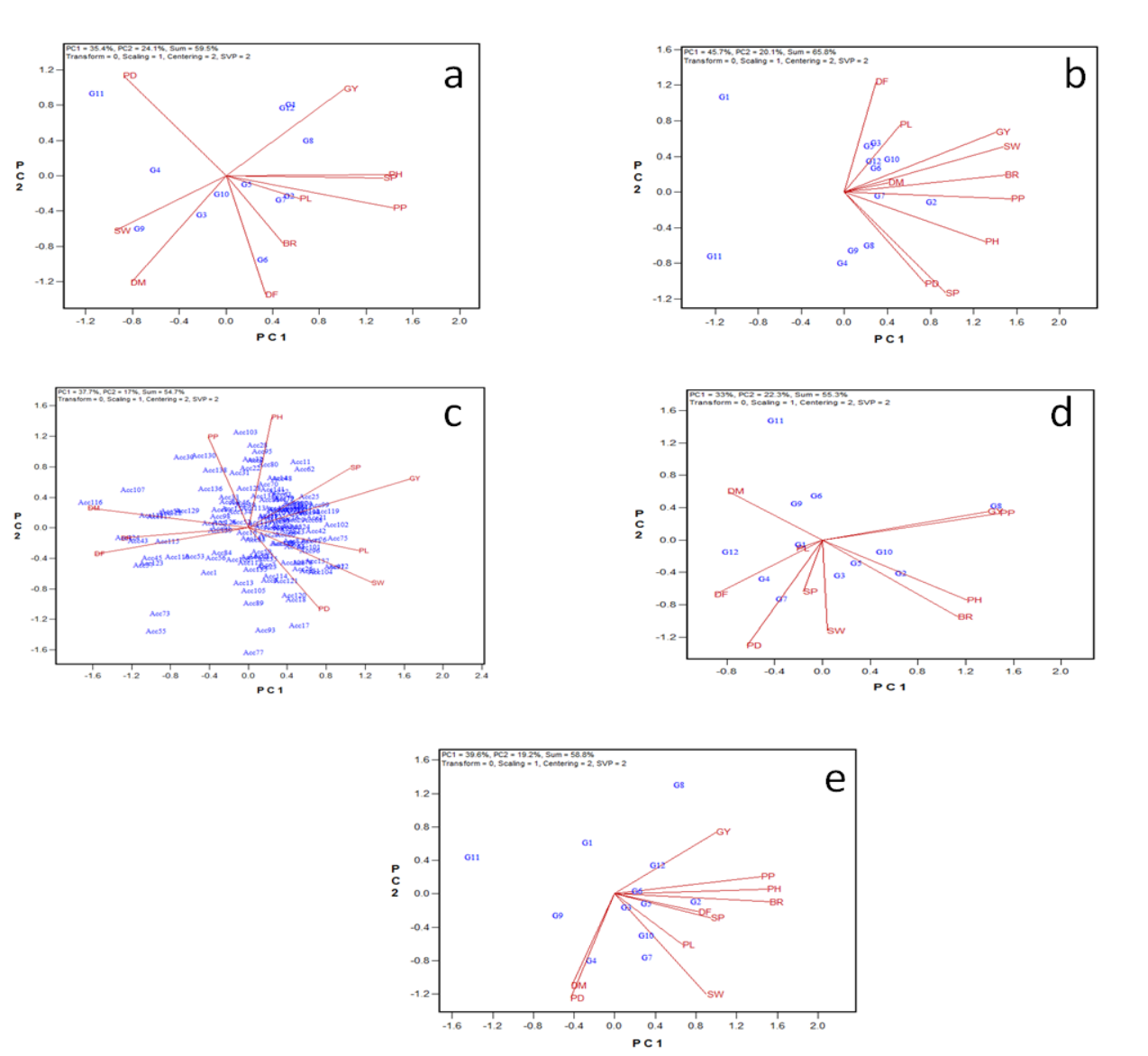

Fig 1. Biplots showing the interrelationships among different traits for white lupin landraces evaluated in different scenarios. (a) In high altitude environments (Debre Tabor and Injibara); (b) In mid-altitudes (Fenote Selam and Merawi); (c) At Merawi which evaluated 143 landrace accessions; (d) In low altitude environments (Dibate and Mandura); and (e) Across six testing sites representing highland, mid altitude and lowland ecologies. G1 - G12 are codes for white lupin landraces evaluated in all the six environments; whereas Acc1 - Acc144 in figure 'c' are codes to represent accessions phenotyped at Merawi, Ethiopia. GY = Grain yield; $\mathrm{PP}=$ Pods per plant; $\mathrm{SP}=$ Seeds per pod; $\mathrm{SW}=100$ seed weight; $\mathrm{PH}=$ Plant height; $\mathrm{BR}=$ Number of branches on the main axis; $\mathrm{PL}=$ Pod length; $\mathrm{PD}=$ Pod diameter; $\mathrm{DF}=$ Days to flowering; and $\mathrm{DM}=$ Days to physiological maturity. 
Table 2. Pearson correlations coefficients among grain yield and related traits in Ethiopian white lupin landraces based on Genotype by trait data generated from different agro-ecologies of Ethiopia.

\begin{tabular}{|c|c|c|c|c|c|c|c|c|c|c|c|}
\hline Traits & DF & DM & BR & $\mathrm{PH}$ & PD & PL & PP & SP & SW & GY & \\
\hline DF & & 0.627 & 0.398 & 0.105 & -0.522 & 0.388 & 0.188 & 0.081 & -0.085 & -0.127 & DF \\
\hline $\mathrm{DM}$ & 0.044 & & 0.002 & -0.378 & -0.126 & 0.066 & -0.307 & -0.379 & 0.32 & -0.636 & DM \\
\hline BR & 0.002 & -0.419 & & 0.158 & -0.423 & -0.033 & 0.254 & 0.127 & 0.031 & 0.028 & BR \\
\hline PH & -0.123 & -0.415 & 0.821 & & -0.429 & 0.275 & 0.672 & 0.643 & -0.27 & 0.493 & $\mathrm{PH}$ \\
\hline PD & 0.322 & -0.132 & 0.046 & 0.067 & & -0.025 & -0.689 & -0.351 & -0.047 & 0.089 & PD \\
\hline PL & -0.033 & -0.166 & -0.02 & -0.182 & 0.027 & & 0.234 & 0.308 & -0.211 & 0.194 & PL \\
\hline PP & -0.626 & -0.346 & 0.471 & 0.564 & -0.402 & -0.261 & & 0.74 & -0.332 & 0.21 & PP \\
\hline SP & 0.127 & -0.283 & 0.127 & -0.095 & 0.415 & 0.759 & -0.124 & & -0.332 & 0.244 & SP \\
\hline SW & 0.068 & 0.017 & 0.334 & 0.31 & 0.579 & -0.305 & -0.129 & -0.075 & & -0.751 & SW \\
\hline GY & -0.533 & -0.323 & 0.445 & 0.407 & -0.547 & 0.095 & 0.762 & 0.089 & -0.081 & & GY \\
\hline
\end{tabular}

(b). Twelve accessions evaluated at two mid-altitude environments (above diagonal) and 143 white lupin landraces evaluated at Merawi (below

\begin{tabular}{|c|c|c|c|c|c|c|c|c|c|c|c|}
\hline Traits & DF & DM & BR & PH & PD & PL & PP & SP & SW & GY & \\
\hline DF & & -0.245 & 0.282 & -0.099 & -0.174 & 0.075 & 0.017 & -0.357 & 0.451 & 0.426 & DF \\
\hline DM & 0.649 & & -0.061 & 0.017 & 0.321 & 0.317 & 0.214 & -0.134 & 0.346 & 0.342 & DM \\
\hline BR & 0.611 & 0.462 & & 0.726 & 0.207 & 0.29 & 0.875 & 0.485 & 0.78 & 0.733 & BR \\
\hline $\mathrm{PH}$ & -0.153 & 0.073 & -0.061 & & 0.504 & 0.258 & 0.663 & 0.698 & 0.532 & 0.449 & $\mathrm{PH}$ \\
\hline PD & -0.077 & -0.287 & -0.157 & -0.222 & & -0.396 & 0.318 & 0.522 & 0.391 & 0.191 & PD \\
\hline PL & -0.276 & -0.4 & -0.218 & 0.052 & 0.371 & & 0.294 & -0.002 & 0.24 & 0.304 & PL \\
\hline PP & 0.143 & 0.277 & 0.244 & 0.278 & -0.096 & -0.04 & & 0.629 & 0.787 & 0.795 & PP \\
\hline SP & -0.296 & -0.402 & -0.307 & 0.234 & 0.07 & 0.266 & 0.107 & & 0.211 & 0.157 & SP \\
\hline SW & -0.383 & -0.508 & -0.183 & -0.032 & 0.416 & 0.443 & -0.264 & 0.162 & & 0.933 & SW \\
\hline GY & -0.744 & -0.667 & -0.517 & 0.284 & 0.119 & 0.38 & 0.071 & 0.482 & 0.458 & & GY \\
\hline
\end{tabular}

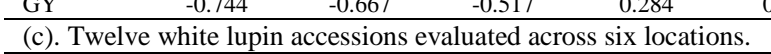

\begin{tabular}{|c|c|c|c|c|c|c|c|c|c|c|}
\hline Traits & DF & DM & BR & $\mathrm{PH}$ & PD & PL & PP & SP & SW & GY \\
\hline DF & & -0.153 & 0.354 & 0.299 & 0.084 & 0.302 & 0.196 & 0.121 & 0.366 & 0.507 \\
\hline $\mathrm{DM}$ & -0.153 & & -0.156 & -0.255 & 0.168 & 0.294 & -0.183 & -0.313 & 0.433 & -0.449 \\
\hline BR & 0.354 & -0.156 & & 0.826 & -0.338 & 0.26 & 0.877 & 0.37 & 0.604 & 0.427 \\
\hline PH & 0.299 & -0.255 & 0.826 & & -0.27 & 0.319 & 0.774 & 0.527 & 0.448 & 0.48 \\
\hline PD & 0.084 & 0.168 & -0.338 & -0.27 & & 0.038 & -0.447 & 0.318 & 0.273 & -0.273 \\
\hline PL & 0.302 & 0.294 & 0.26 & 0.319 & 0.038 & & 0.173 & 0.269 & 0.365 & 0.167 \\
\hline PP & 0.196 & -0.183 & 0.877 & 0.774 & -0.447 & 0.173 & & 0.459 & 0.478 & 0.35 \\
\hline SP & 0.121 & -0.313 & 0.37 & 0.527 & 0.318 & 0.269 & 0.459 & & 0.219 & 0.318 \\
\hline SW & 0.366 & 0.433 & 0.604 & 0.448 & 0.273 & 0.365 & 0.478 & 0.219 & & -0.057 \\
\hline GY & 0.507 & -0.449 & 0.427 & 0.48 & -0.273 & 0.167 & 0.35 & 0.318 & -0.057 & \\
\hline
\end{tabular}

$\mathrm{DF}=$ Days to \% flowering; DM= Days to maturity; BR=Number of primary branches on the main axis; PH=Plant height in centimeter; PD=Pod diameter in millimeter; PL= Pod length in millimeter; $\mathrm{PP}=$ Pods per plant; $\mathrm{SP}=$ Seeds per pod; $\mathrm{SW}=100$ seed weight in gram; $\mathrm{GY}=$ Grain yield in tons per hectare.

a

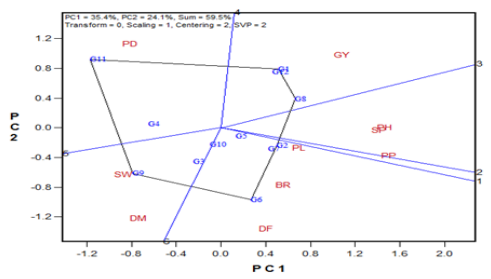

$\mathrm{b}$
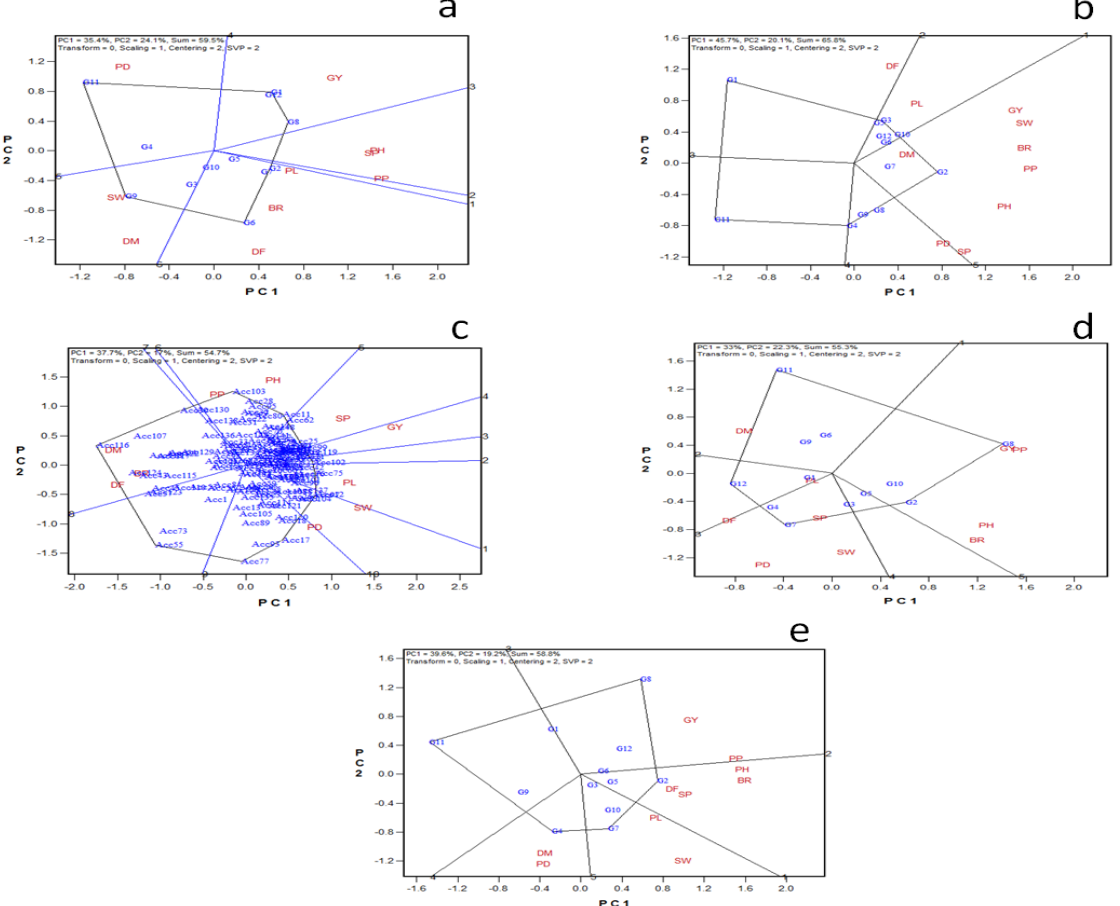

Fig 2. Polygon view of the genotype by trait biplot for different environments in Ethiopia, demonstrating white lupin landrace comparison on the basis of a GT biplot. (a) High altitude (Injibara and Debre Tabor) environments; (b) Mid-altitude (Fenote Selam and Merawi) environments; (c) Merawi which evaluated 143 landrace accessions; (d) Low altitude (Dibate and Mandura) environments; and (e) Across six testing sites representing highland, mid altitude and lowland ecologies. G1 - G12 are codes for white lupin landraces evaluated in all the six environments; whereas Acc1 - Acc144 in figure ' $c$ ' are codes to represent accessions phenotyped at Merawi, Ethiopia. GY = Grain yield; PP = Pods per plant; SP = Seeds per pod; SW = 100 seed weight; PH = Plant height; $\mathrm{BR}=$ Number of branches on the main axis; $\mathrm{PL}=$ Pod length; $\mathrm{PD}=$ Pod diameter; $\mathrm{DF}=$ Days to 50\% flowering; and $\mathrm{DM}=$ Days to $95 \%$ physiological maturity. 
additive gene action in governing the expression of the trait and consequently high expected genetic gain through selection. High estimates of heritability and low genetic advance observed for some of the traits suggest the presence of non-additive gene action and/or significant genotype by environment interaction in the expression of the traits that will make selection difficult for the improvement of these traits. Several researchers reported similar results to the present finding on different legume and other crop species, such as mungbean (Payasi, 2015), soybean (Malek et al., 2014), cowpea (Ajayiet al., 2014), ricebean (Geeta et al., 2015), and barley (Dyulgerova and Valcheva, 2014).

\section{Trait relationships and trait profiles in white lupin landraces}

Different trends of trait associations and trait profiles were observed under different environments due to genotype by location interaction effects, as depicted by the GT biplot for different locations in this study (Fig 1a -e). Annicchiarico et al. (2010) reported similar finding in white lupin accessions evaluated in Italy and France. The important question here is, which of the biplots should be chosen? The biplot in Figure 1e, for example, may be regarded as an integration of the GT patterns from all trials conducted across location, but it is not $100 \%$ true to any of the single location trial. These conflicting patterns were caused by, and were an indication of, genotype by location interactions. In such cases, GT data analysis by mega-environment could be a solution (Yan, 2014). Thus, the GT biplots that reveal trait relationships and trait profiles of white lupin landraces used in this study are presented and discussed following altitude based megaenvironments.

GT biplots in this study captured 55\% - 66\% of the variations due to genotype and genotype by trait interactions. As previous report by Yan and Rajcan (2002), this result reflects the complexity of the interrelationships among the measured traits. Nevertheless, the fundamental patterns among the traits could still be captured by the biplots (Kroonenberg, 1995). Similar results were reported by Rubio et al. (2004) for white lupin accessions evaluated in Spain. In the biplot, the cosine of the angle between two traits approximates the correlation between the traits; and hence associations among traits could easily be visualized from the biplot. Two traits are positively correlated if the angle between the vectors is acute $\left(<90^{\circ}\right)$; negatively correlated if the angle is obtuse $\left(>90^{\circ}\right)$; and not correlated if the angle is right angle (Yan and Tinker, 2006). These associations could be confirmed from Pearson correlation coefficients between any two traits (Table 2). However, some discrepancies might be expected as the biplots explained only $55-65 \%$ of the variations attributed to the genotype and genotype by trait interactions. In higher altitude locations (Injibara and Debre Tabor), grain yield had strong and positive association only with plant height; positive relationship with seeds per pod, pods per plant and pod length; and positive but weak associations with pod diameter and days to flowering as revealed by the acute angles between the vectors of these traits (Fig 1a). Results of Pearson correlation coefficients showed similar relationship among these traits (Table 2a). On the other hand, grain yield had significantly negative correlation with days to maturity and hundred seed weight. In agreement with the current study, Rubio et al. (2004) reported positive associations between grain yield and plant height in white lupin genotypes evaluated in Spain. Traits that had strong positive associations have a tendency to discriminate accessions in similar fashions, whereas traits with negative associations have a tendency to discriminate accessions in opposite direction.

At mid altitude environments (Fenote Selam and Merawi), however, grain yield had positive associations with all measured traits, with relatively stronger relationship with hundred seed weight, pods per plant, branch number and plant height (Fig1b; Table 2b). In the comprehensive experiment, similar associations were observed between grain yield and most other traits ( Fig 1c; Table 2b). However, grain yield had negative relationships with phenological traits (days to flowering and days to maturity) and branch number on the main axis. This could be due to an excessive and extended rainy period occurred at Merawi during the experimentation, which significantly delayed the flowering and maturity period. Grain yield had strong and positive relationships with plant height, pods per plant and branch number on the main axis in the low altitude environments (Dibate and Mandura). On the other hand, grain yield was negatively associated with hundred seed weight, days to flowering and pod diameter (Fig 1d; Table 2a). Strong positive relationship between grain yield and pods per plant was previously reported in white lupin genotypes (Huyghe et al., 1990).

Trait relationships based on data averaged over six locations for the focused experiment revealed that grain yield had positive relationship with all traits measured except with days to maturity, pod diameter and hundred seed weight (Fig 1e; Table 2c). Although the GT biplot captured most important relationships, it did not entail all the associations that have been apparent between traits in the respective mega-environments. Hence, it is advisable to consider trait associations under the context of mega-environments as presented in this paper. The inconsistencies in associations of some of the traits over different environments might be due to environmental effects and genotype by environment interactions. The length of the trait vector projected from the origin shows the ability of the traits in discriminating among accessions. Traits with longer vectors do have high discrimination power and vice versa. Thus, grain yield and most agronomic traits had longer vectors, and hence high discrimination power. Whilst pod length and number of branches on the main axis consistently showed shorter projection of vector in all environments; and days to maturity, days to flowering, 100 seed weight and seeds per pod had shorter vectors in some of the environments. This indicates the inability of these traits to discriminate among the accessions in the respective environments.

A genotype may be regarded as a package of traits; genotype evaluation must be based on multiple traits that are considered as breeding objectives (Yan, 2014). In the focused experiment, the genotypes were evaluated for multiple traits across locations and a polygon view of the which -winswhere biplots of GT were constructed based on mean values of the traits (Fig 2a-e). The biplots identified the best accession (s) for specific trait or group of traits. Accordingly, landraces G1, G2, G6, G8, G9 and G11 were vertex genotypes; and hence, were the most responsive in high altitude environments (Fig 2a). Vertex accessions show higher values for the traits that fall within the same sector in the biplot (Yan et al., 2007). Hence, in the highland ecology, G1 and G8 had the higher grain yield; G2 had the highest number of pods per plant and longest pods; G6 had the highest number of branches and was the latest in flowering; G9 had the heaviest seed weight and was the latest in maturity; and G11 had wider pod diameter than the other accessions. However, GT relationships observed in the highland ecologies were not consistent with the relationships 
observed in other ecologies. For example, in the mid-altitude ecology (Fig 2b), G2 had the highest mean values for seven out of the 10 measured traits, except for days to maturity, pod length and diameter. In contrary, G11 had the lowest performance for all the traits considered. In the low altitude environments, G2 and G8 showed desirable performances for grain yield, pods per plant, plant height and branch number whereas G7 had higher number of seeds per pod, larger seeds, and longer pods but flowered late. G2 showed taller plant height, higher number of branches, and higher number of seeds per plant but delayed in flowering. G8 had the highest grain yield and number of pods per plant. G7 had more number of pods per plant and larger seed and G4 produced longer pods and matured later whereas G11 had lower values for all the traits measured. The polygon view of the genotype by trait biplot for the data combined across locations (Figure 2e) showed that accessions G8 and G2 had higher grain yield, whereas G11 followed by G9 and G4 had lower grain yield. G8 also showed better grain yield in the highland (Figure 2a) and lowland (Figure 2d) ecologies, indicating the inherent higher yield potential of these accessions. Hence, G8 could be recommended for further exploitation in the breeding programs.

Figure 2c presents trait profiles of 143 white lupin landrace accessions evaluated at Merawi. The biplot gave more opportunity to assess which accessions were good for which trait (s) that would help as excellent baseline information for white lupin improvement in Ethiopia and elsewhere. This biplot is divided into 10 sectors; out of which three sectors are without traits. Sectors without traits indicate that the accessions falling in these sectors including the vertex accessions, for instance Acc55, Acc102 and Acc30, had low values for all the traits studied. On the other hand, sectors in which both accessions and traits fell could clearly and visually depict the best accession for each trait. For instance, accession (Acc119) is the vertex accession in the grain yield (GY) sector and hence the accession was the highest yielder, and Acc103 had more pods per plant (PP) and the tallest plant height $(\mathrm{PH})$ in that particular sector.

\section{Materials and Methods}

\section{Germplasm}

Two independent experiments were conducted under this study. The first one, which is a comprehensive experiment consisted of 143 Ethiopian landrace white lupin accessions and one narrow leafed lupin genotype introduced from Germany. The Ethiopian landraces used in this study represent almost $50 \%$ of the total collections conserved at the Ethiopian Biodiversity Institute (EBI). The accessions were mainly collected from northwestern Ethiopia; viz, Gojam and Gondar, while few accessions were included from Southern and Northern parts of Ethiopia. Detail descriptions and passport data; and map of collection area of the accessions are provided as Supplementary Table 1a and Supplementary Figure 1. The second experiment focused on 12 white lupin landrace accessions (Supplementary Table 1b) selected from the first experiment based on desirable performance for grain yield and resistance to major lupin diseases such as lupin rust, pleiochaeta root rot, brown leaf spot and phomopsis (Atanf et al., 2015b).

\section{Experimental design and field management}

The comprehensive experiment was executed at Merawi, North western Ethiopia during 2013/2014 season with supplemental irrigation. Detail description of Merawi experimental location is given in Supplementary Table 2 . The experiment was laid out in a $12 \times 12$ simple lattice design. Each plot consisted of two rows of $2.5 \mathrm{~m}$ length with spacing of $75 \mathrm{~cm}$ and $25 \mathrm{~cm}$ between rows and between plants, respectively. The seeds were hand planted in rows. As there is no research recommended fertilizer rate for white lupin growing in Ethiopia, fertilizer was not used for this experiment. Supplementary irrigation was applied as necessary. Other agronomic management and crop protection practices were applied uniformly to all the plots during the period of experimentation. The focused experiment was conducted in the main season of 2014/15 over six locations; namely, Debre Tabor, Injibara, Merawi, Fenote Selam, Dibate and Mandura. These locations represent major lupin growing areas of Ethiopia. Detail descriptions of the test locations are presented in Supplementary Table 2. Completely randomized block design with four replications was used for this experiment. Each experimental unit consisted an area of $15 \mathrm{~m}^{2}(5 \mathrm{~m} \times 3 \mathrm{~m})$ with similar intra-row and inter-row spacing with the comprehensive experiment. Planting, fertilization, agronomic management and crop protection practices used were similar to that of the comprehensive experiment.

\section{Data collection}

For both experiments, data were recorded for grain yield and agronomic traits. Grain yield was recorded on plot basis in grams, and adjusted to $14 \%$ moisture content and expressed as tons per hectare $\left(\mathrm{tha}^{-1}\right)$. Hundred seed weight $(\mathrm{gm})$ was determined using random seeds from each experimental unit after grain moisture content was adjustment to $14 \%$. Number of days from emergence to $50 \%$ flowering and $75 \%$ physiological maturity were recorded as days to flowering and days to maturity, respectively. Number of pods per plant, number of branches on the main axis and plant height $(\mathrm{cm})$ were recorded as the average of five randomly selected plants per plot. Five randomly selected pods from each of these plants were used to record number of seeds per pod, pod length $(\mathrm{mm})$ and diameter $(\mathrm{mm})$.

\section{Data analysis}

All the data collected were checked for outliers and normality of residuals using Breeding View of Breeding Management System before proceeding to any subsequent analysis (BMS, 2015). Consequently, an outlier accession (Acc144), which was found to significantly affect the result was excluded from the subsequent analyses of the comprehensive experiment. The same software was used to generate adjusted mean values for all the traits using best linear unbiased estimators (BLUE).

Phenotypic and genotypic coefficients of variations, genetic advance as percent of mean, and heritability in broad sense were estimated using the formula suggested by Singh and Chaudhary (1985) as follows:

$P C V=\frac{\sqrt{\delta^{2} p}}{\bar{X}} X 100$
$G C V=\frac{\sqrt{\delta^{2} g}}{\bar{X}} X 100$
$\delta \mathrm{p}=\sqrt{\delta^{2}}$
$H=\frac{\delta^{2} g}{\delta^{2 p}}$
$G A M=\frac{H K \delta_{p}}{\bar{X}} X 100$ 
where, $\delta_{\mathrm{p}}^{2}$ and $\delta_{\mathrm{g}}^{2}$ are phenotypic and genotypic variances, respectively; PCV and GCV are phenotypic and genotypic coefficients of variation, respectively; $\bar{X}$ is the grand mean; $\mathrm{H}$ is the broad sense heritability; GAM is genetic advance as percent of mean; $\delta_{\mathrm{p}}$ is phenotypic standard deviation; and $\mathrm{K}$ is selection differential at 5\% selection intensity (2.06).

For the interpretation of genetic parameters, heritability values were categorized as suggested by Robinson et al. (1949): $0-30 \%$ as low, $30-60 \%$ as moderate, and $>60 \%$ as high. The values of GAM were categorized as recommended by Johnson et al. (1955): $0-10 \%$ as low, $10-20 \%$ as moderate, and $>20 \%$ as high.

Adjusted mean values of the traits were used for the analysis of genotype by trait and trait associations. The adjusted mean values were standardized to mean zero and unity variance in order to minimize biases due to differences in scales of measurement. To display the genotype by trait two-way data in a biplot, the formula suggested by Yan and Rajcan (2002) was used:

$\frac{T_{i j}-\bar{T}_{j}}{s j}=\lambda_{1} \zeta_{i 1} \tau_{j 1}+\lambda_{2} \zeta_{i 2} \tau_{j 2}+\varepsilon i j$

where, $T_{i j}$ is the average value of genotype $i$ for trait $j, T_{j}$ is the average value of trait $j$ over all genotypes, $s_{j}$ is the standard deviation of trait $j$ among the genotype averages; $\zeta i_{1}$ and $\zeta \mathrm{i}_{2}$ are the first principal component (PC1) and the second principal component (PC2) scores, respectively, for genotype $i, \tau_{\mathrm{J} 1}$ and $\tau_{\mathrm{J} 2}$ are the PC1 and PC2 scores, respectively, for trait $j$, and $\varepsilon_{i j}$ is the residual of the model associated with the genotype $i$ and trait $j$.

Equation [6] is a principal component analysis of standardized data with two principal components. Because different traits use different units, the standardization is necessary to remove the units.

PC1 and PC2 must be scaled so that the one value is symmetrically distributed between the genotype scores and the trait scores. A GT biplot is constructed by plotting the PC1 scores against the PC2 scores for each genotype and each trait. To display the PC1 and PC2 in a biplot, the $\lambda$ values in Equation [6] above are absorbed into the genotype and trait scores so that the equation is written as:

$\frac{T_{i j}-\bar{T}_{j}}{s j}=\zeta_{i 1} \tau_{j 1}+\zeta_{i 2} \tau_{j 2}+\varepsilon i j$

In addition, Pearson correlation coefficients were computed using GGE software to augment the trait relationships visualized in the GT biplot. Moreover, GT analysis was done following mega-environments classification approach. A mega-environment is a sub-region of a crop species' growing region within which the same or similar genotypes perform best (Gauch and Zobel, 1997). Understanding the megaenvironment constitution of the target region for a given crop is a prerequisite for determining proper strategies of genotype evaluation and cultivar recommendation.

\section{Conclusion}

Significance differences were observed for most traits among the white lupin accessions used in the current study, indicating the presence of considerable amount of genetic variations among Ethiopian white lupin local accessions. The study revealed high estimates of GCV, heritability and genetic advance as percent of mean for grain yield which indicates the possibility of improving this most important trait through selection. Trait associations and trait profiles were found to be different for different environments due to genotype by location interactions. Analysis of trait relationships and trait profiles based on averaged data over all locations captured most important relationships and trait profiles, though it did not entail all the associations and profiles apparent in the respective mega-environments as the biplots explained $55 \%-66 \%$ of the variations. Nevertheless, the current results indicated the need to consider trait associations and trait profiles under the context of different mega-environments. GT biplots were found to be effective to reveal and visualize important relationships among attributes and trait profiles of Ethiopian white lupin landraces for ease multi-variate selection.

\section{Acknowledgements}

The study was part of $\mathrm{PhD}$ research work of the first author (MA) and he is grateful to the financial support of Ethiopian Institute of Agricultural Research (EIAR) and Pawe Agricultural Research Center through Sustainable Intensification of Maize-Legume Systems for Food Security in Eastern and Southern Africa (SIMLESA) project funded by the Australian Government. The local accessions were kindly provided by the Ethiopian Biodiversity Institute (EBI). MA would also like to thank researchers at respective locations for their assistance in trial management.

\section{Reference}

Abu NE, Uguru MI, Obi IU (2011) Genotype by trait relations of yield and yield components in aromatic peppers (Capsicum annuum) based on GT biplot. J Plant Breed Crop Sci. 3: 382 - 390.

Ajayi AT, Adekola MO, Taiwo BH, Azuh VO (2014) Character expression and differences in yield potential of ten genotypes of cowpea (Vigna unguiculata L.). Plant. 4: 63-71.

Akcura M (2011) The relationships of some traits in Turkish winter bread wheat landraces. Turk J Agric For. 35:115125.

Ali A, Khan S, Asad MA (2002) Drought tolerance in wheat: genetic variation and heritability for growth and ion relations. Asian J Plant Sci. 1:420-422.

Allard RW (1960) Principles of plant breeding.1st ed., John Wiley and Sons INC., New York.

Annicchiarico P, Harzic N, Carroni AM (2010) Adaptation, diversity, and exploitation of global white lupin (Lupinus albus L.) landrace genetic resources. Field Crops Res. 119:114-124.

Atanf M, Tesfaye K, Kifle D (2015a) The importance of legumes in the Ethiopian farming system and overall Economy: an overview. Am J Exp Agric.7:347-358.

Atnaf M, Tesfaye K, Dagne K, Wegary D (2015b) Extent and pattern of genetic diversity in Ethiopian white lupin landraces for agronomical and phenological traits. Afr Crop Sci J. 23: 327 - 341.

Dyulgerova B, Valcheva D (2014) Heritability, variance components and genetic advance of yield and some yield related traits in barley doubled haploid lines. Turk J Agric Nat Sci. Special Issue 1:614-617.

Gauch H, Zobel RW (1997) Identifying mega-environments and targeting genotypes. Crop Sci. 37:311-326.

Geeta P, Rajendra P, Birendra P, Priyamvada C (2015) Co-efficient of variation, heritability, genetic advance and variability for ricebean (Vigna umbellata (Thunb.) genotypes under mid hill conditions of Uttarakhand. J Appl Nat Sci. 7: 794 - 798.

González AM, Monteagudo AB, Casquero PA, De Ron AM, Santalla M (2006) Genetic variation and environmental effects on agronomical and commercial quality traits in the 
main European market classes of dry bean. Field Crops Res. 95:336-347.

Gonzalez-Andres F, Casquero PA, San-Pedro C, HernandezSanchez E (2007) Diversity in white lupin (Lupinus albus L.) landraces from Northwest Iberian plateau. Genet Resour Crop Ev. 54: 27-44.

Hall RS (2005) Australian sweet lupin flour addition reduced the glycaemic index of a white bread breakfast without affecting palatability in healthy human volunteers. Asia Pac J Clin Nutr. 14: 91-97

Hirpa L, Nigussie D, Setegn G, Geremew B, Firew M (2013) Multivariate analysis as a tool for indirect selection of common bean genotypes (Phaseolus vulgaris L) for soil acidity tolerance under field conditions. Sci Technol Arts Res J. 2: 07-15.

Huyghe C (1990) Discussion of selection criteria for grain yield in lupin breeding. In: Birk V, Dovrat A, Waldman M, Uzureau $\mathrm{C}(\mathrm{Eds})$ Lupin production and bio-processing for feed, food and other by-products. Proc. Joint CEC-NCRD workshop, state of Israel ministry of science and technology, Ginozar Kibbutz, 21-30 January. 1990.

Johnson HW, Robinson HF, Comstock RE (1955) Estimates of genetic and environmental variability in soybean. Agron J. 47: $314-318$.

Johnson SK, Chua V, Hall RS, Baxter AL (2006) Lupin kernel fiber foods improve bowel function and beneficially modify some putative faecal risk factors for colon cancer in men. Brit J Nutr. 95:372-8.

Kroonenberg PM (1995) Introduction to biplots for $\mathrm{G} \times \mathrm{E}$ tables. Department of Mathematics, research report 51, University of Queensland.

Kurlovich BS (2002) The history of lupin domestication. Chapter 5. In: Kurlovich BS(Ed.) Lupins (geography, classification, genetic resources, and breeding). OY International North Express. St. Petersburg, RussiaPellosniemi, Finland. pp. 147-164.

Lewis RS (2006) Identification of germplasm of possible value for confronting an unfavorable inverse genetic correlation in tobacco. Crop Sci. 46:764-771.

Lqari H, Pedroche J, Girion-Calle J, Vioque J (2005) Production of lupinus angustifolius protein hydrolysates with improved functional properties. Grasas Aceites. 56: 135-140.

Ma BL, Yan W, Dwyer LM, Fregeau-Reid J, Voldeng HD, Dion Y, Nass H (2004) Graphic analysis of genotype, environment, nitrogen fertilizer, and their interactions on spring wheat yield. Agron J. 96:169-180.

Malek MA, Rafii MY, Shahida S, Afroz M, et al. (2014) Morphological characterization and assessment of genetic variability, character association, and divergence in soybean mutants. Sci World J. Article ID 968796, 12 pages

Oladejo AS, Akinwale RO, Obisesan IO (2011) Interrelationships between grain yield and other physiological traits of cowpea cultivars. Afr Crop Sci J. 19: $189-200$

Panse VG (1957) Genetics of quantitative characters in relation to plant breeding. Indian J Genet Pl Br. 28: 225229.

Payasi DK (2015)Genetic variability analysis for seed yield and its components in mungbean (Vignaradiata L. Wilczek). Int J Plant Breed Genet. 9: 177-188.

Peter MV, William GH, Naomi RW (2008) Heritability in the genomics era: concepts and misconceptions. Nat Rev Genet. 9:255-267.
Raman R, Cowley RB, Raman HD, Luckett J (2014) Analyses using SSR and DArT molecular markers reveal that Ethiopian accessions of white lupin (Lupinus albus $L$.) represent a unique gene pool. Open J Genet. 4:87-98.

Reza M, Ahmed A (2011) Graphic analysis of trait relations and genotype evaluation in durum wheat. J Crop Improv. 25: 680-696.

Robinson HF, Comstock RE, Harvey PH (1949) Estimates of heritability and degree of dominance in corn. Agron J. 42: $353-359$

Rubio J, Cubero JI, Martin LM, Suso MJ, Flores F (2004) Biplot analysis of trait relations of white lupin in Spain. Euphytica. 135: 217-224.

Singh B (2000) Plant breeding: principles and methods (6th ed.). Kalyani Publishers, New Delhi.

Singh RK, Chaudhary BD (1985) Biometrical methods in quantitative genetic analysis. Kalyani Publishers, New Delhi.

Tazeen M, Nadia K, Farzana NN (2009) Heritability, phenotypic correlation and path coefficient studies for some agronomic characters in synthetic elite lines of wheat. J Food Agric Environ. 7: 278 - 282.

The IBP Breeding Management System Version 3.0.9 (2015) The integrated breeding plat form. https://www.integrated breeding.net/ breeding-management-system.

Wolko B, Clements JC, Naganowska B, Nelson MN, Yang H (2011) Lupinus. In: C Kole (ed.) Wild crop relatives: genomic and breeding resources. Springer. Berlin, Heidelberg. pp 153-206.

Xiao Xu Z, Jian-Ping G, Shu-Min W, Qing-Chang L, Robert R, Rebecca F (2008) Genetic diversity and core collection of alien (Pisum sativum L.) germplasm. Acta Agron Sin. 34: 1518-1528.

Yan W (2014) Genotype-by-trait data analysis and decisionmaking. Chapter 9. In: Yan W (ed.)Crop variety trials: data management and analysis, 1st ed. John Wiley \& Sons, INC., New York. pp 163-186.

Yan W, Rajcan IR (2002) Biplot analysis of test sites and trait relations of soybean in Ontario. Can J Plant Sci. 42:11-20.

Yan W, Fregeau-Reid J (2008) Breeding line selection based on multiple traits. Crop Sci. 48:417-423.

Yan W, Hunt LA, Sheng Q, Szlavnics Z (2000) Cultivar evaluation and mega-environment investigation based on GGE biplot. Crop Sci. 40:597-605.

Yan W, Kang MS (2003) GGE-biplot analysis: a graphical tool for breeders. Geneticists and agronomists. CRD Press, Boca Raton.

Yan W, Tinker NA (2006) Biplot analysis of multienvironment trial data: principles and applications. Can J Plant Sci. 86: 623-645.

Yan W, Tinker NA, Molnar S, Fregeau-Reid J, McElroy A (2007) Associations among oat traits and their responses to the environment in North America. J Crop Improv. 20:1-29.

Yeheyis L, Kijora C, van Santen E, Wink M, Danier J, Peters KJ (2012) Crude protein, amino acid and alkaloid contents of annual sweet lupin (Lupinus Spp. L.) forages and seeds grown in Ethiopia. Expl Agric. 48:414-427.

Yeheyis L, Kijora C, Solomon M, Anteneh G, Peters KJ (2010) White lupin (Lupinus albus L.), the neglected multipurpose crop: its production and utilization in the mixed crop-livestock farming system of Ethiopia. Livestock Res Rural Develop. 22(4). Article \#74. 